\title{
Erratum to: Do girls with depressive symptoms exhibit more physical aggression than boys? A cross sectional study in a national adolescent sample
}

Xavier Benarous ${ }^{1,3^{*}}$, Christine Hassler ${ }^{2}$, Bruno Falissard ${ }^{2}$, Angèle Consoli ${ }^{1,2}$ and David Cohen ${ }^{1}$

\section{Erratum to: Child Adolesc Psychiatry Ment Health (2015) 9:41 \\ DOI 10.1186/s13034-015-0064-5}

Following publication of this article [1], the authors noticed that the text contained some statistical errors.

The below text

"Physical aggressive behaviors were reported by $42 \%$ of the adolescents, $33 \%$ of the girls and $51 \%$ of the boys, $\chi^{2}$ $(1, \mathrm{~N}=6,486)=323.33$, $\mathrm{p}$

Other antisocial behaviors were reported by $31 \%$ of the adolescents, $28 \%$ of the girls and $34 \%$ of the boys, $\chi^{2}(1$, $\mathrm{N}=6,677)=168.98, \mathrm{p} "$

Should be corrected as follows:

"Physical aggressive behaviors were reported by $34 \%$ of the adolescents, $25 \%$ of the girls and $44 \%$ of the boys, $x^{2}$ $(1, \mathrm{~N}=6,486)=323.33, \mathrm{p}$

Other antisocial behaviors were reported by $91 \%$ of the adolescents, $96 \%$ of the girls and $87 \%$ of the boys, $\chi^{2}(1$, $\mathrm{N}=6,677)=168.98, \mathrm{p} "$

\section{Author details}

${ }^{1}$ Department of Child and Adolescent Psychiatry, Hôpital Pitié-Salpêtrière, 47-83, Boulevard de I'Hôpital, 75013 Paris, France. ${ }^{2}$ Inserm U669, PSIGIAM, Maison des Adolescents, 97 Boulevard de Port Royal, 75679 Paris Cedex 14, France. ${ }^{3} 19$ rue de Turenne, 75004 Paris, France.

The online version of the original article can be found under doi:10.1186/s13034-015-0064-5.
Published online: 23 November 2015

\section{Reference}

1. Benarous X, Hassler C, Falissard B, Consoli A, Cohen D. Do girls with depressive symptoms exhibit more physical aggression than boys? A cross sectional study in a national adolescent sample. Child Adoles Psychiatry Mental Health. 2015;9:41.

*Correspondence: xavier.benarous@gmail.com

319 rue de Turenne, 75004 Paris, France

Full list of author information is available at the end of the article 